\title{
Virtual reality trajectory of modified PUMA 560 by hybrid intelligent controller
}

\author{
Yousif I. Al Mashhadany \\ Department of Electrical Engineering, College of Engineering, University of Anbar, Iraq
}

\begin{tabular}{l}
\hline \hline Article Info \\
\hline Article history: \\
Received Dec 26, 2019 \\
Revised Apr 12, 2020 \\
Accepted Jul 11, 2020 \\
\hline
\end{tabular}

\section{Keywords:}

Hybrid ANFIS controller Industrial applications FOPID controller Modified PUMA 560

Virtual reality

\begin{abstract}
The high performance is a goal for all designers to get better, faster, or more efficient than others. This paper proposes a design for virtual reality (VR) of modified PUMA 560 by hybrid controller between adaptive neuro fuzzy inference system (ANFIS) controller and fractional order proportional, integral, derivative (FOPID) controller. The main purpose is to obtain the optimal trajectory by get the best value of controller's parameters that regulate the manipulator movements smoothly to the desired target. The procedure of design start by obtains the optimal values of the traditional PID controller parameters normally. The next step is applied the FOPID controller with high accuracy. It is high performance to control the perplexing physics system than, the classical integer order of PID controller. The final step to get high performance of the control system under considers is achieved by hybrid between FOPID with ANFIS controller which used the pervious output as predictive point. The whole proposed hybrid controller model was simulated and reproduction by MATLAB Version 2019b and Robotic system Toolbox 9. The optimal design of this controller is applied with 3D model of modified PUMA 560 which design by using VR technique under MATLAB/Simulink.
\end{abstract}

This is an open access article under the $\underline{C C B Y-S A}$ license.

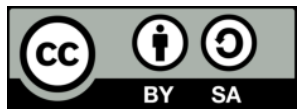

\section{Corresponding Author:}

Yousif I. Al Mashhadany, Department of Electrical Engineering, College of Engineering, University of Anbar, Iraq.

Email: yousif.mohammed@uoanbar.edu.iq

\section{INTRODUCTION}

Clever control frameworks increment the adequacy of control systems and defeat points of confinement of old style and versatile controllers. They are relied upon to have in-manufactured adjustment/learning and basic leadership capacities to deal with vulnerabilities so the ideal execution can be accomplished $[1,2]$. To beat customary figuring worldview limits, specialists search for new computational ways to deal with incomplete displaying of neural framework usefulness and that can take care of certifiable issues viably. Novel computational models have risen, all in all called delicate figuring. Joining insight into delicate figuring are artificial neural system (ANN), fluffy rationale, ANFIS, genetic algorithm (GA), and information-based master frameworks [3-5]. Insightful self-learning or self-arranging control of master frameworks, man-made consciousness or artificial intelligence (AI), fuzzy logic (FL), neural system or neural network $(\mathrm{NN})$, cross breed systems, and so on are the new presentation improving apparatuses of modern force gadgets with drive plant [6]. Fuzzy logic presented by Zadeh with first form in 1965 [7, 8]. It forms information by means of fractional, instead of fresh, set participation. Like neural system, FL can create unmistakable ends from obscure, vague, uncertain, and missing, input data. An appropriate fuzzy inference system (FIS) is basic to rectifying fluffy enrollment capacities and fluffy standards yet building it requires some investment and necessities significant mastery [9-11]. 
Joining an idea of fuzzy rationale with artificial neural system, it is a cross breed canny framework that improves programmed learning and adjustment. Specialists have utilized such a framework to anticipate and display in different building frameworks. Fundamental to neuro-versatile learning strategies is a fluffy displaying technique that learns a FL at that point gains from the information it is demonstrating. Change of the participation work limits needn't bother with a human administrator, so this is a preferred position over unadulterated fluffy worldview [12-15].

Nonstop and dull assignments of creation many parameters such as: tuning, lines are weakness can produce mishap/damage or long haul medical issues. The robot controller arm can more than once convey immense and substantial parts starting with one generation line then onto the next, so is these days widely utilized in processing plants to build effectiveness and handle rehashed/risky/sensitive undertakings (e.g., semiconductor wafer creation) [16-19].

Repetition of the robot controller can be beneficial when the DOF of a given errand is not as much as that of the controller. At the point when a joint disappointment happens, the robot controller is as yet ready to play out its undertaking dependably. Solitary arrangement of the robot controller can be maintained a strategic distance from by controlling repetition through powerful converse Jacobian peculiarity [20, 21]. To help ANFIS development, fuzzy subtractive bunching groups the accessible information into fuzzy bunches. FL subtractive bunching works superior to does different FIS grouping techniques. Distinctive span mixes create diverse FIS, as shown in Figure 1. Picking the correct powerful to a given issue is along these lines significant [22].

$$
\begin{aligned}
& R_{a}^{1} \text { :if } \quad x_{i} \text { is } A_{1}^{1} \text { and } x_{j} \text { is } A_{2}^{1} \text {, then } f f_{1}=p_{A} x_{i}+p_{A} x_{j}+r_{1} \\
& R_{a}^{2}: \text { if } \quad x_{j} \text { is } A_{1}^{2} \text { and } x_{j} \text { is } A_{2}^{2} \text {, then } f f_{2}=p_{B} x_{i}+p_{B} x_{j}+r_{2}
\end{aligned}
$$

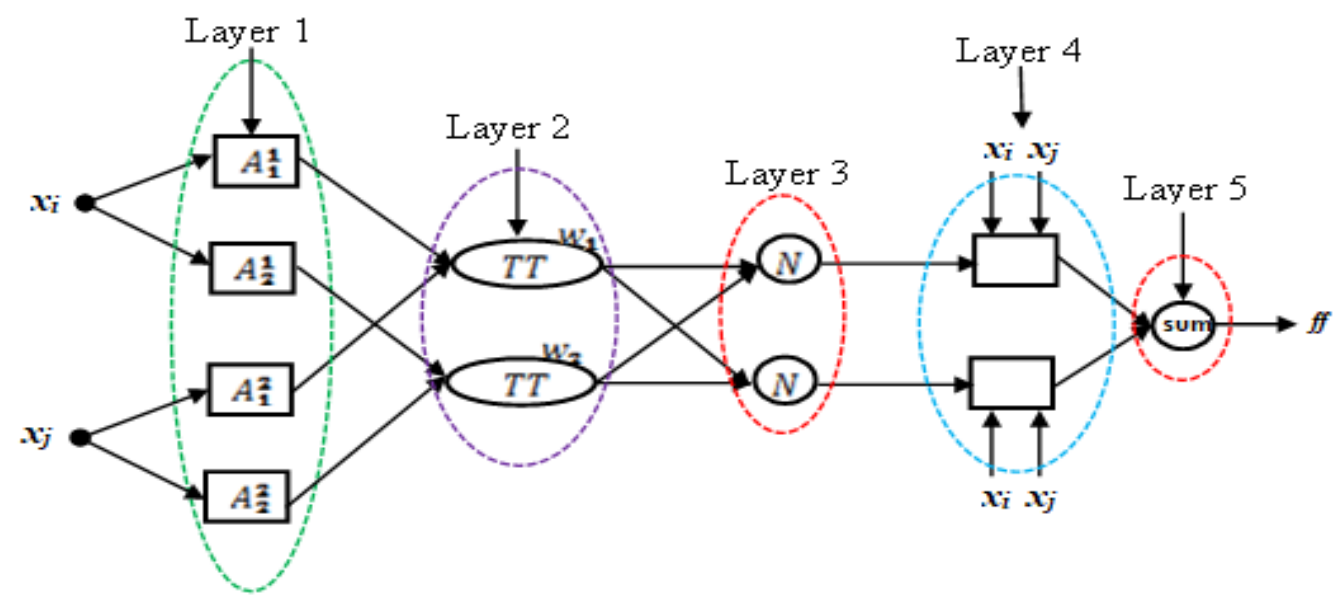

Figure 1. Structure of Sugeno-Takagi FIS based on (12)

\section{INVERSE KINEMATIC SOLUTION OF MODIFIED PUMA 560}

The measure of joints chooses DOF controller. The normal support in any occasion must have 6 self-ruling DOF: situating has three and three for heading. In cases lass the 6-DOF, the blast can't arrive at a gauge course for each point in its working environment. Applications, for instance, are spreading over around or behind hindrances need more than 6 DOF. Extended connections, apart from this, create control problems (the console with more than six connections is known as the dynamically repeated controller). Workspace is the comprehensive volume that is scanned by the end effector through all possible developments in the console set. It is bound by the control engineering and mechanical limitations of the joints [23-26]. Direct-driving the robot wipes out apparatus issues of backfire, contact, and consistence. The coupling among the connections, in any case, is progressively noteworthy, and the engine elements might be substantially more perplexing. To extricate better from this kind of controller, an alternate arrangement of control issues must be tended to [27]. 
We presents in this work the proposal of a DMRAC based on ANFIS hybrid with optimized traditional PID controller for a modified PUMA 560 robot, as shown in Figure 2. A balance with controller's shoulder joint marginally confounds with two kinematics solution; forward and inverse. Joint organize outlines are along these lines previously settled by means of DH show (DH parameters are described by Table 1), the Ai matrices can be the calculated as:

$$
\begin{aligned}
& A_{1 a}=\left[\begin{array}{cccc}
c_{a 1} & 0 & s_{a 1} & 0 \\
s_{a 1} & 0 & -c_{a 1} & 0 \\
0 & 1 & 0 & d_{a 1} \\
0 & 0 & 0 & 1
\end{array}\right] ; A_{2 a}=\left[\begin{array}{cccc}
c_{a 2} & 0 & s_{a 2} & a_{2} \\
s_{a 2} & 0 & -c_{a 2} & 0 \\
0 & 1 & 0 & 0 \\
0 & 0 & 0 & 1
\end{array}\right] \\
& A_{3 a}=\left[\begin{array}{cccc}
c_{a 3} & 0 & -s_{a 3} & a_{3} \\
s_{a 3} & 0 & c_{a 3} & 0 \\
0 & 1 & 0 & 0 \\
0 & 0 & 0 & 1
\end{array}\right] ; A_{4 a}=\left[\begin{array}{cccc}
c_{a 4} & 0 & -s_{a 4} & 0 \\
s_{a 4} & 0 & c_{a 4} & 0 \\
0 & 1 & 0 & 0 \\
0 & 0 & 0 & 1
\end{array}\right] \\
& A_{5 a}=\left[\begin{array}{cccc}
c_{a 5} & 0 & s_{a 5} & 0 \\
s_{a 5} & 0 & -c_{a 5} & 0 \\
0 & 1 & 0 & 0 \\
0 & 0 & 0 & 1
\end{array}\right] ; A_{6 a}=\left[\begin{array}{cccc}
c_{a 6} & 0 & s_{a 6} & 0 \\
s_{a 6} & 0 & c_{a 6} & 0 \\
0 & 1 & 0 & d_{6 a} \\
0 & 0 & 0 & 1
\end{array}\right]
\end{aligned}
$$

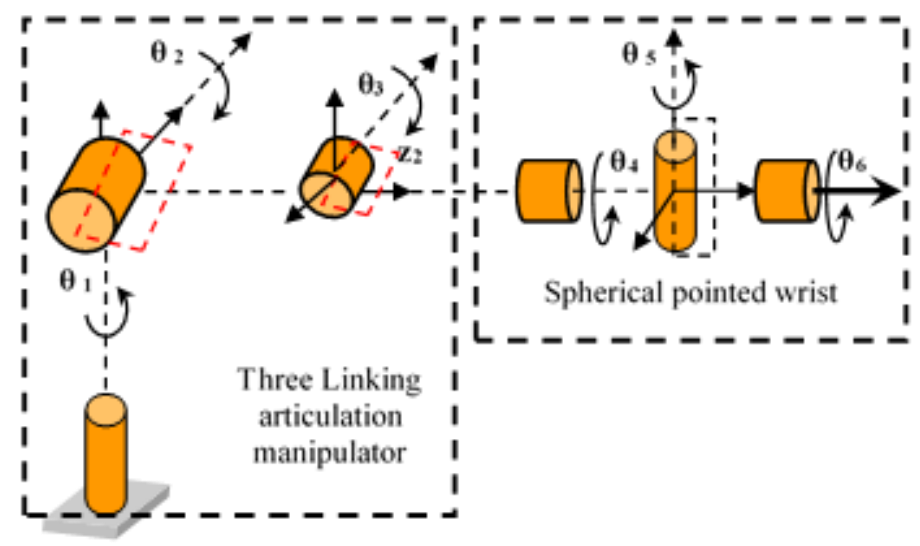

Figure 2. Modified PUMA 560 robot structure

Table 1. The description of DH parameters of the modified PUMA 560 parameters

\begin{tabular}{ccccc}
\multicolumn{5}{c}{$(*$ denoted to Joint Variable) } \\
\hline Link & $\mathrm{di}$ & $\mathrm{ai}$ & $\alpha \mathrm{i}$ & $\mathrm{Q} \mathrm{i}$ \\
\hline $\mathrm{L}_{1 \mathrm{a}}$ & $\mathrm{d}_{1 \mathrm{a}}$ & 0 & $\pi / 2$ & $\mathrm{Q}_{1 \mathrm{a}}$ \\
$\mathrm{L}_{2 \mathrm{a}}$ & 0 & $\mathrm{a}_{2 \mathrm{i}}$ & 0 & $\mathrm{Q}_{2 \mathrm{a}}$ \\
$\mathrm{L}_{3 \mathrm{a}}$ & 0 & $\mathrm{a}_{3 \mathrm{i}}$ & 0 & $\mathrm{Q}_{3 \mathrm{a}}$ \\
$\mathrm{L}_{4 \mathrm{a}}$ & 0 & $-\pi / 2$ & 0 & $\mathrm{Q}_{4 \mathrm{a}}$ \\
$\mathrm{L}_{5 \mathrm{a}}$ & 0 & $\pi / 2$ & 0 & $\mathrm{Q}_{5 \mathrm{a}}$ \\
$\mathrm{L}_{6 \mathrm{a}}$ & $\mathrm{D}_{6 \mathrm{a}}$ & 0 & 0 & $\mathrm{Q}_{\mathrm{a}}$ \\
\hline
\end{tabular}

The solution of mathematical parameters of trajectory and controller assumed the end-effector with point (o) and its direction with $\mathrm{R}=\left(\right.$ rij), while the wrist center at $\left(\mathrm{o}_{\mathrm{c}}\right)$, now we can get (3). $\mathrm{R}$ presents the direction of the edge $\mathrm{o}_{6} \mathrm{X}_{6} \mathrm{y}_{6} \mathrm{Z}_{6}$ comparative with the starting point (base). In the event that parts (o) is the position of final traget are bull up $\mathrm{o}_{\mathrm{x}}, \mathrm{o}_{\mathrm{y}}, \mathrm{o}_{\mathrm{z}}$ while a segment of robot wrist community position are $\mathrm{x}_{\mathrm{c} 1}$, $\mathrm{y}_{\mathrm{c} 1}, \mathrm{z}_{\mathrm{c} 1},(3)$ will give this relationship. 


$$
\begin{aligned}
& o_{c}^{o}=o-d_{6 a} R_{a}\left[\begin{array}{l}
0 \\
0 \\
1
\end{array}\right] ; \quad \&\left[\begin{array}{l}
x_{c 1} \\
y_{c 1} \\
z_{c 1}
\end{array}\right]=\left[\begin{array}{l}
x_{c 1}-d_{6} r_{13} \\
y_{c 1}-d_{6} r_{23} \\
z_{c 1}-d_{6} r_{33}
\end{array}\right] \\
& q_{11}=a \tan 2\left(x_{c 1}, y_{c 1}\right) ; \quad q_{31}=\tan ^{-1}\left(\frac{ \pm \sqrt{1-D_{a}^{2}}}{D_{a}}\right) \\
& \text { where: } D_{a}=\frac{x_{c 1}^{2}+y_{c 1}^{2}-d_{a 6}^{2}+\left(z_{c 1}-d_{a 1}\right)^{2}-a_{2}^{2}-a_{3}^{2}}{2 a_{2} a_{3}} \\
& q_{21}=\tan ^{-1}\left(\frac{z_{c 1}-d_{1}}{\sqrt{x_{c 1}^{2}+y_{c 1}^{2}-d^{2}}}\right) ; \quad q_{41}=\tan ^{-1}\left(\frac{-c_{1} s_{23} r_{13}+s_{1} s_{23} r_{23}+c_{23} r_{33}}{c_{1} c_{23} r_{13}+s_{1} c_{23} r_{23}+s_{23} r_{33}}\right\} \\
& q_{51}=\tan ^{-1}\left(\frac{ \pm \sqrt{1-\left(s_{1} r_{13}-c_{1} r_{23}\right)^{2}}}{s_{1} r_{13}-c_{1} r_{23}}\right) ; \quad q_{61}=\tan ^{-1}\left(\frac{s_{1} r_{12}+c_{1} r_{22}}{-s_{1} r_{11}+c_{1} r_{21}}\right)
\end{aligned}
$$

The solution of kinematics is obtained by expository arrangement with course of action of the above conditions. General responses for the upheaval edges are as sketched out underneath. Subbing $\mathrm{d}_{1 \mathrm{a}}=20 \mathrm{~cm}$, $\mathrm{d}_{6 \mathrm{a}}=15 \mathrm{~cm}, \mathrm{a}_{2}=22 \mathrm{~cm}$, and $\mathrm{a}_{3}=20 \mathrm{~cm}$ for the target of end-effector and its directions at $20,40,10, \pi / 3,-\pi / 3$, and $\pi / 3$ will get the final form in (5). In genuine applications, for the robot to communicate with its condition, an appropriate consistence in Cartesian space must be indicated. Utilization of agreeable, as opposed to solid, position control has likewise been proposed, essentially to keep away from the enormous powers coming about because of a hardened robot arm's contact with nature (particularly if the earth is obscure and unstructured).

$$
\left.\begin{array}{cc}
x_{c 1}=12 \mathrm{~cm}, \quad y_{c l}=25 \mathrm{~cm}, & z_{c l}=20 \mathrm{~cm}, D=30 \mathrm{~cm}, \\
q_{11}=0.5646 \mathrm{rad}, & q_{21}=0.6981 \mathrm{rad}, \\
q_{31}=q_{31}=1.3408 \mathrm{rad}, & q_{41}=-1.9425 \mathrm{rad}, \\
q_{51}=0.3986 \mathrm{rad}, & q_{31}=2.5649 \mathrm{rad}, \\
q_{61}=5.9832 e^{-17} \mathrm{rad},
\end{array}\right\}
$$

\section{INTELLIGENT CONTROLLER SYSTEM DESIGN}

The design of proposed controller depends on reality and accuracy for invers kinematics solution. The training of intelligent part of ANFIS controller used the real data from kinematic solution. The second part of controller is FOPID was implemented by classical procedure of controller design. It is apply PID controller design with classical analysis of system performance. The fundamental structure of the new controller presents by Figure 3. Displaying of the old style controller can be executed as controller-structure technique (e.g., experimentation). ANFIS controller's underlying condition, wiping out the distinguishing proof fundamental in other versatile control methods.

The ANFIS controllers with FOPID controller yields are added. Post-beginning, the preparation for parameters is identified with ANFIS controller's parameters as demonstrated by fuzzy change getting ready standards (explained straightaway). The old style FOPID controller is tuning the components $\mathrm{K}_{\mathrm{p}}, \mathrm{K}_{\mathrm{i}}, \mathrm{K}_{\mathrm{d}}$ withdrew before utilizing them; they address the concealed arranging states of the proposed intelligent controller. 


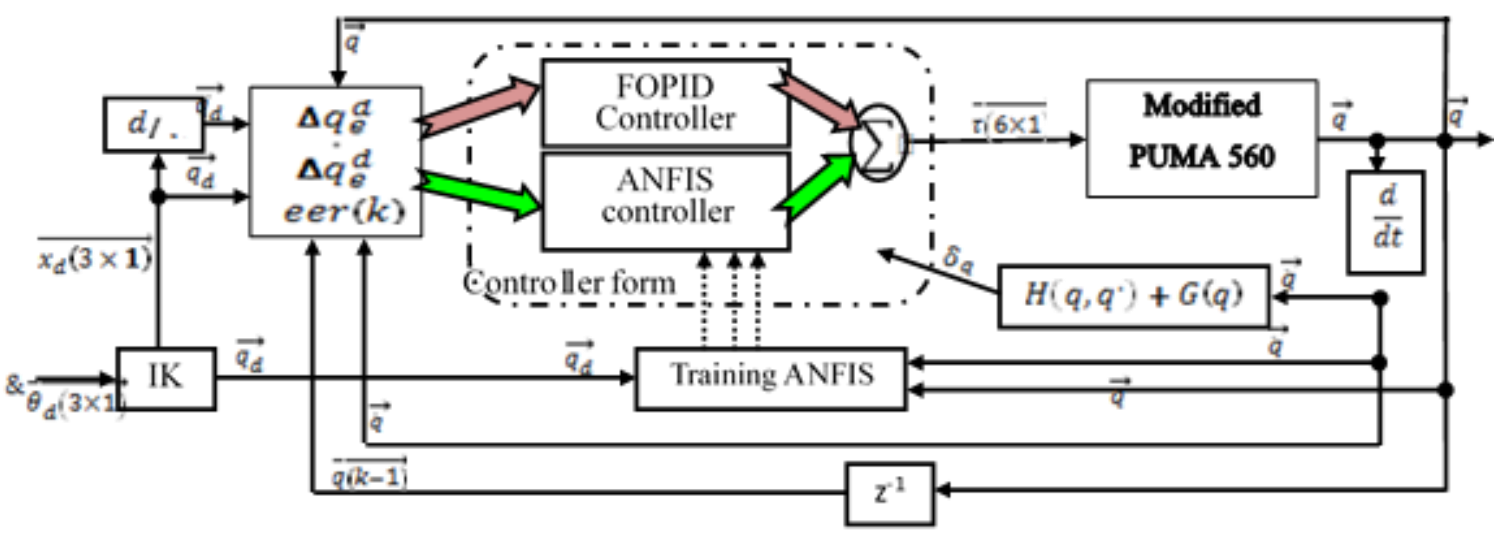

Figure 3. Overall block diagram of hybrid intelligent controller

\section{ANIMATION MODEL FOR THE MODIFIED PUMA 560 ROBOT}

VRML is one of the most important design programs for $3 \mathrm{D}$ objects, coordinating their input and controlling their output based on real physical hypotheses for all system modeling parameters. This program was used in the design of the arm (including) developed in this work because it provides many facilities in the design of these models. The VRML Builder is distinguished by its written software for modeling and training the 6-DOF robot arm and configuring its working environment.

There is a huge difference in the updates that programs are treated with VRML and MATLAB. The coordinates that use VRML, where the coordinate (in y-axis) indicates the top of the triangular model, while the coordinate (in x-axis) represents the left and right of the model, while the coordinate (in z-axis) represents the dimension and proximity to the screen of the VRML program as shown in Figure 4.

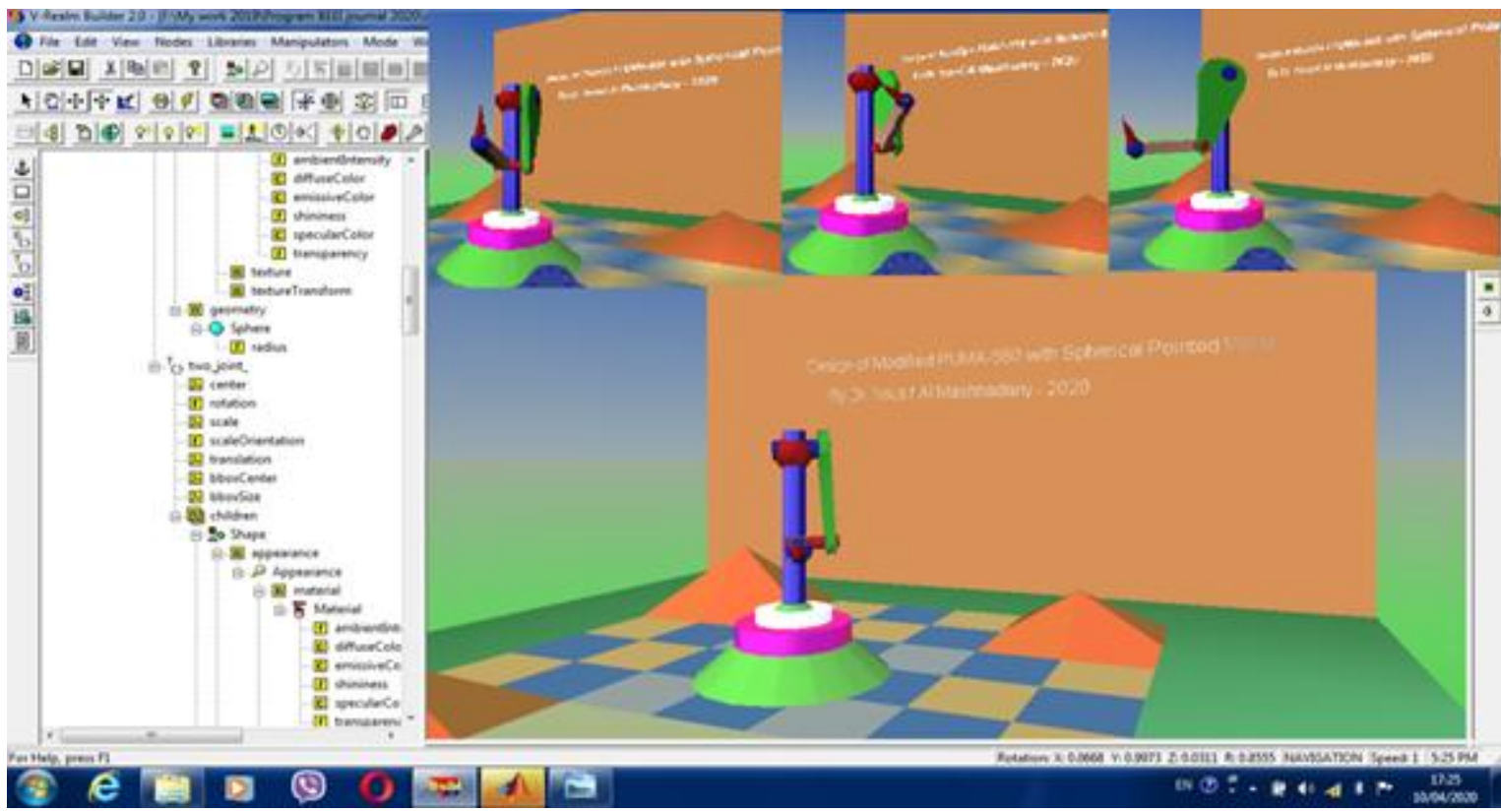

Figure 4. Modified PUMA 560 robot model based on virtual reality enivorment

The design in this work presents in Figure 4, I used the integrated time correlation between virtual reality and the MATLAB program by linking the instructions between the Simulink environment and the triple model in VRML by calculating and configuring orders and linking the implementation of the instructions that are executed through the main processor of the computer with the orders that are implemented in the triple model with quantities and physical measurements that Pre-prepared and calculated at the stage of calculating the mathematical model of the arm. 


\section{SIMULATION OF PROPOSED DESIGN}

The structure proposed by the VR environment was presented by Matlab software Ver. 2019b with Robotic system Toolbox 9. The cloning began by an unshakable quality inspection of the old and half-style ANFIS console (which by chance is faster and more accurate than the conventional console alone). The ANFIS console was tried in half and half on different exchange work models, and its versions were contradictory and the console was in the old style as shown in Figure 5. Model exchange capabilities (T.F) are:

$$
T . F . a(s)=\frac{1}{s^{2}+7 s+6} \quad \text { or } \quad T . F . b(s)=\frac{1}{s^{3}+12 s^{2}+20 s+18}
$$
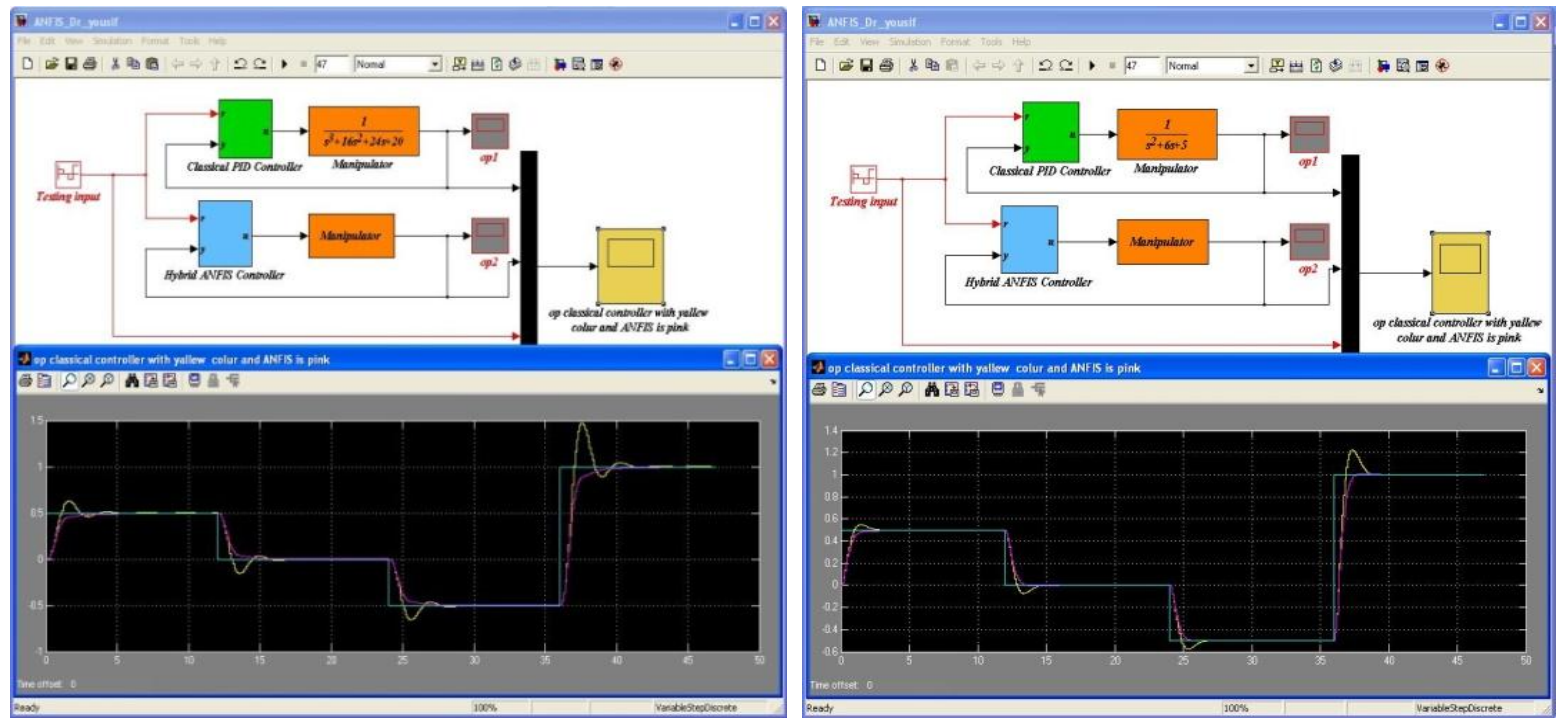

Figure 5. Simulation of proposal design of intelligent controller

The simulation results for proposed design of intelligent controller explained the high performance of system design. it is clear from classical analysis of outputs. The simulation achieved by using practical initialization parameters because the presents of 3D model need the high accuracy of simulation to get accurate trajectory. Figure 6 presents 3D MATLAB simulation of modified PUMA 560 recreation of the IK solution.

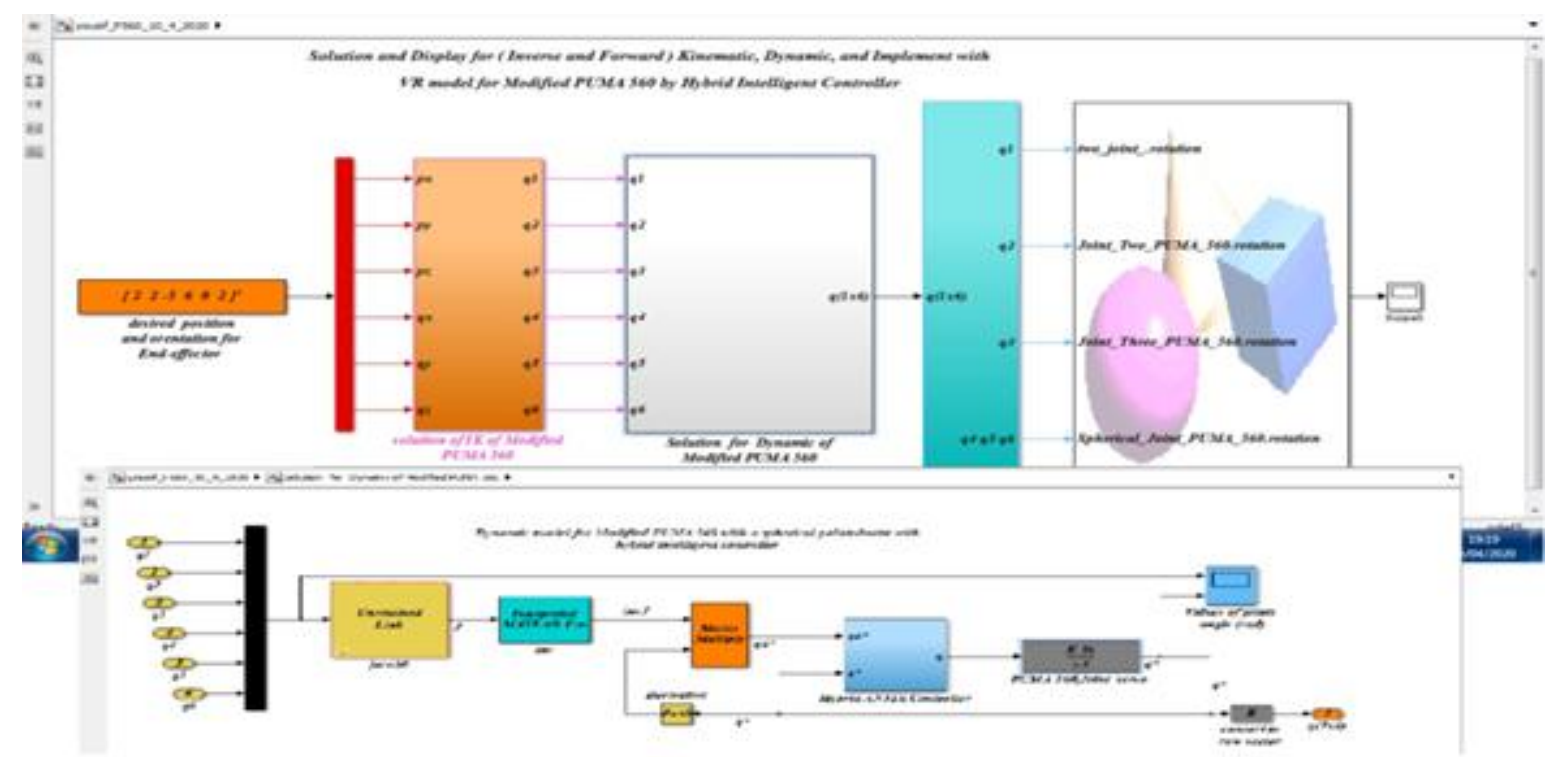

Figure 6. Simulation of Inverse kinematic solution and dynamic response 
Figure 7 presents the simulation of VR model for modified PUMA 560 by using the hybrid intelligent controller. The modified PUMA 560 performance testing by checking accuracy of getting the target point by optimal trajectory, the speed of apply the instructions, and the reliability implementation of poroposed resulting by using the hybrid intehhlgent controller. The implementation of trajectory depends on the accuracy of calculation of joints angle for selected job. the results with different complex pathes for modified PUMA 560 improve the ability of consider the setting parameters of this model as practical robot with different application such as industrial, biomedical and eduction. Figure 8 presents different posture and its trajectory, the using spherical pointed gripper offer for this robot to apply high complex tasks and can be depends this model for very accurate applications.

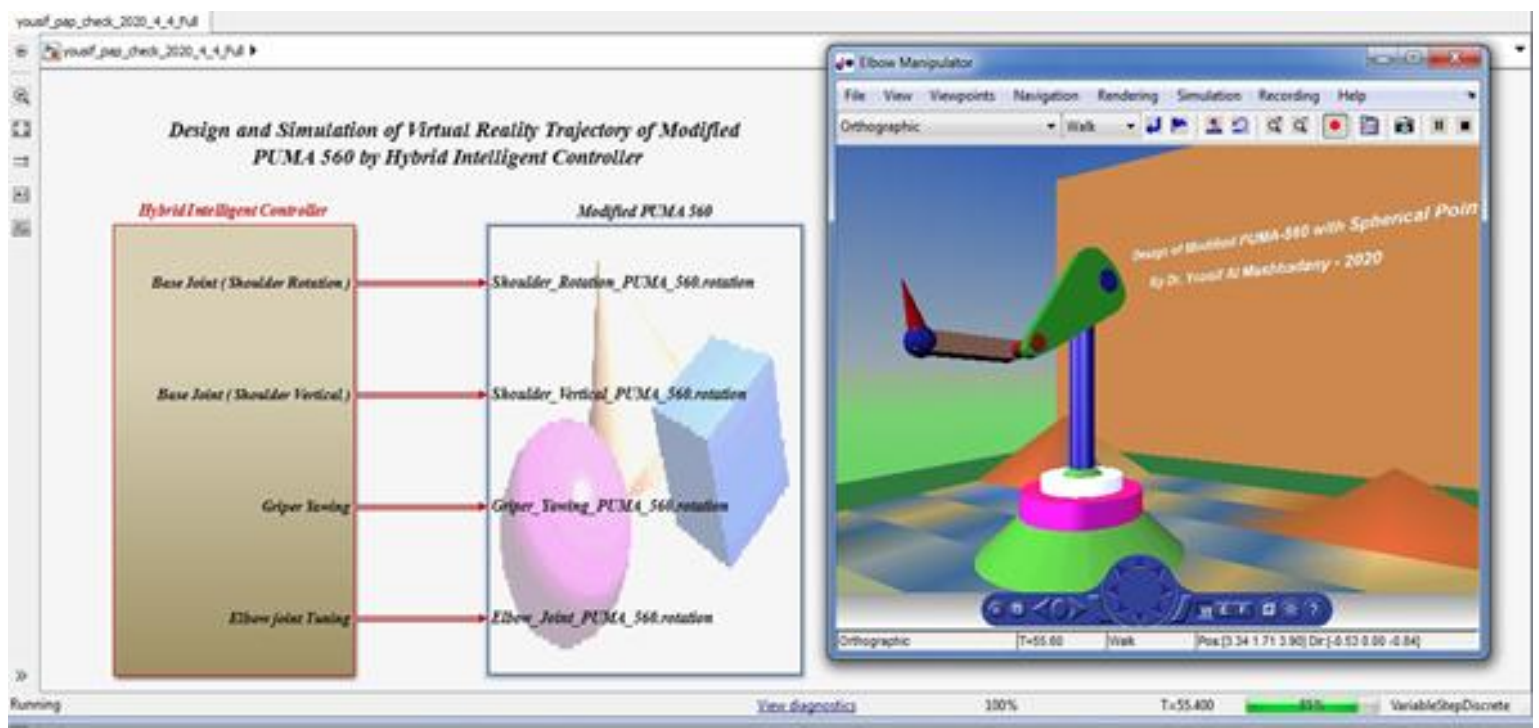

Figure 7. Final simulation form of modified PUMA 560 with hybrid intelligent controller

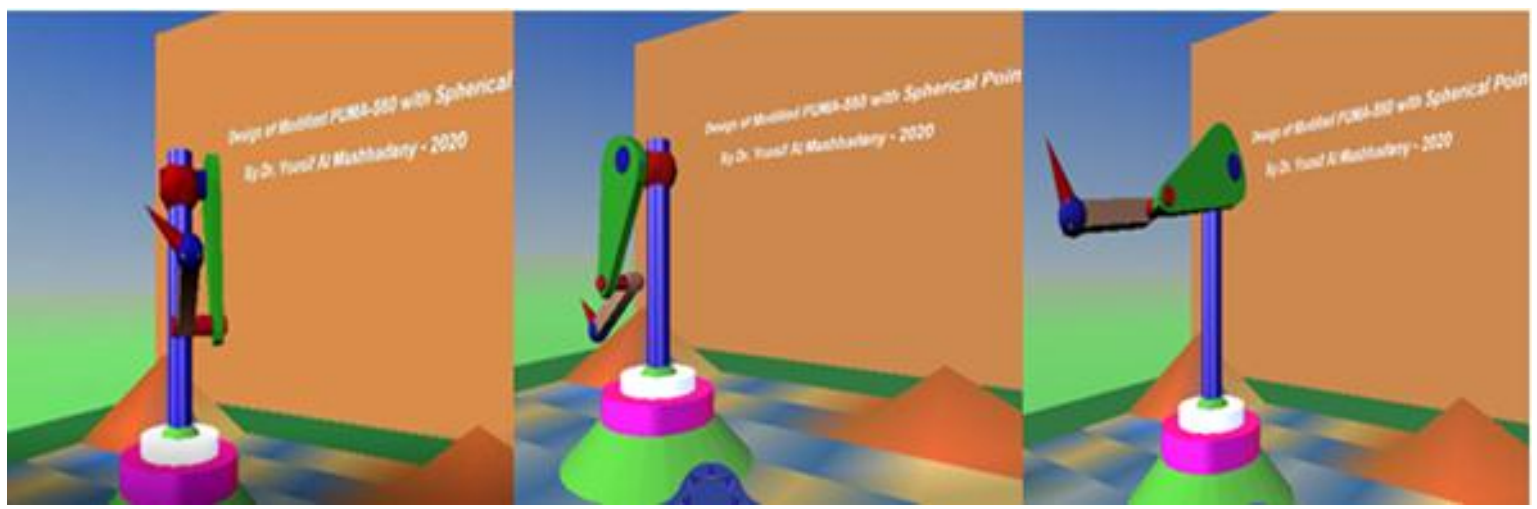

Figure 8. Postures of the modified PUMA 560 in different trajectories

\section{CONCLUSIONS}

The solution of kinematic to get imagining for performance is inferred in $\mathrm{D}-\mathrm{H}$ documents. Performance of simulation was made by VR technique with MATLAB Var. 2019b by using Robot Tool No.9. Simulated results with optimized hybrid intelligent controller configuration allow checking robot parameters through forward and reverse kinematics. This encourages the structure, development and review of original robots. The high ability to adapt ANFIS controller methodology is appropriate for wide range of control applications in the field of biomedical, industrial, biophysicists process and static-dynamic nuclear control process, it is difficult to obtain a strong, specific brand through direct setup (this exploration uses a direct crossover MRAC and thus can The framework error is constantly limited). The palatable recreation results demonstrate the feasibility of the proposed plot. An examination of the entertainment consequences of

Virtual reality trajectory of modified PUMA 560 by hybrid intelligent controller (Yousif I. Al Mashhadany) 
both the usual and semi-linear ANFIS console shows extended framework methods that reduced overtaking and leveling times, resulting in a significant reduction in native implementations. This work crossed the proposed new ANFIS console according to optimized an old style controller in the framework and changing interactions before retrofitting the cross-strain controller in the frame without reproducing the frame to similarity.

\section{REFERENCES}

[1] Alavandar S., Nigam M. J., "Inverse Kinematics Solution of 3DOF Planar Robot using ANFIS," International Journal of Computers, Communications \& Control, Suppl. issue: Proceedings of ICCCC 2008, vol. III (2008), pp. 150-155, 2008.

[2] A. Izadbakhsh, "Closed-form dynamic model of PUMA 560 robot arm," 2009 4th International Conference on Autonomous Robots and Agents, Wellington, pp. 675-680, 2009.

[3] Xubing Chen, Caihua Xiong and Youlun Xiong, "Kinematics modeling and simulation of a passive four-bar linkage," 2009 International Conference on Mechatronics and Automation, Changchun, pp. 4139-4144, 2009.

[4] Y. A. Mashhadany, K. S. Gaeid and M. K. Awsaj, "Intelligent Controller for 7-DOF Manipulator Based upon Virtual Reality Model," 2019 12th International Conference on Developments in eSystems Engineering (DeSE), Kazan, Russia, pp. 687-692, 2019.

[5] Spong M. W, Hutchinson S, Vidyasagar M, "Robot Dynamics and Control," Second Edition, John Wiley \& Sons, 2004.

[6] Carey R, Bell G, Marrin, C, "ISO/IEC 14772-1:1997 Virtual Reality Modeling Language (VRML97)," available at: ttp://www.vrml.org. 2008.

[7] Sufian Ashraf Mazhari, Surendra Kumar, "Heuristic Search Algorithms for Tuning PUMA 560 Fuzzy PID Controller," World Academy of Science, Engineering and Technology International Journal of Electrical and Information Engineering, vol, 2, no. 9, pp. 2024-2033, 2008.

[8] A. Benitez, I. Huitzil, A. Casiano-Ramos, M. A. Medina and J. De La Calleja, "A 3D simulation environment for kinematic task of the PUMA 560 robot," CONIELECOMP 2011, 21st International Conference on Electrical Communications and Computers, San Andres Cholula, pp. 260-265, 2011.

[9] Y. W. Kean, A. Ramasamy, S. Sukumar and M. Marsadek, "Adaptive Controllers for Enhancement of Stand-Alone Hybrid System Performance," International Journal of Power Electronics and Drive System IJPEDS, vol. 9, no. 3, pp. 979-986, September 2018.

[10] M. Aghajarian and K. Kiani, "Inverse Kinematics solution of PUMA 560 robot arm using ANFIS," 2011 8th International Conference on Ubiquitous Robots and Ambient Intelligence URAI, Incheon, pp. 574-578, 2011.

[11] A. Izadbakhsh, P. Kheirkhahan, "On the Voltage-based Control of Robot Manipulators Revisited," International Journal of Control, Automation and Systems, vol. 16, no. 4, pp. 1887-1894, 2018.

[12] J. L. Patton, G. Dawe, C. Scharver, F. A. Mussa-Ivaldi and R. Kenyon, "Robotics and virtual reality: the development of a life-sized 3-D system for the rehabilitation of motor function," The 26th Annual International Conference of the IEEE Engineering in Medicine and Biology Society, San Francisco, CA, pp. 4840-4843, 2004.

[13] H. Reham, A. Mohammed, E. Basem, B. Elnaghi, A. Fahmy, C. Bendary, "Trajectory Tracking Control and Robustness Analysis of a Robotic Manipulator Using Advanced Control Techniques," International Journal Engineering and Manufacturing, vol. 8, no. 6, pp 42-54, 2018

[14] Y. I. Al-Mashhadany, "Inverse Kinematics Problem (IKP) of 6-DOF Manipulator by Locally Recurrent Neural Networks (LRNNs)," 2010 International Conference on Management and Service Science, Wuhan, pp. 1-5, 2010.

[15] Mustapha Muhammad, et al, "Velocity control of a two-wheeled inverted pendulum mobile robot: a fuzzy modelbased approach," Bulletin of Electrical Engineering and Informatics, vol.8, no.3, pp. 808-817, September 2019.

[16] T. Singaraju, A. Turan, M. Gokasan and S. Bogosyan, "Hardware-in-the-loop simulation of PUMA 560 via internet," IECON 2006 - 32nd Annual Conference on IEEE Industrial Electronics, Paris, pp. 5426-5432, 2006.

[17] A. A. Hussien, Y. I. AL Mashhadany, K. S. Gaeid, M. J. Marie, S. R. Mahdi and S. F. Hameed, "DTC Controller Variable Speed Drive of Induction Motor with Signal Processing Technique," 2019 12th International Conference on Developments in eSystems Engineering (DeSE), Kazan, Russia, 2019, pp. 681-686

[18] Y. I. Al Mashhadany, "SCARA Robot: Modeled, Simulated, and Virtual-Reality Verified," International Conference on Intelligent Robotics Automation and Manufacturing, Springer, Berlin, Heidelberg, pp. 94-102, 2012.

[19] A. Tuan, H. Kang, "An Adaptive Neural Non-Singular Fast-Terminal Sliding-Mode Control for Industrial Robotic Manipulators," Applied Sciences, vol. 8, no. 12, pp 2-17, 2018.

[20] Muhammad Aziz Muslim, et al, "Development of a quadruped mobile robot and its movement system using geometric-based inverse kinematics," Bulletin of Electrical Engineering and Informatic, vol. 8, no. 4, pp.1224-1231, December 2019.

[21] N H-I Lin, C. S. George, "Measurement of the Robot Motor Capability of a Robot Motor System: A Fitts's-LawInspired Approach," Sensors, vol. 13, no. 7, pp. 8412-8430, 2013.

[22] Y. I. Al-Mashhadany, "Modeling and simulation of Adaptive Neuro-Fuzzy controller for Chopper-Fed DC Motor Drive," 2011 IEEE Applied Power Electronics Colloquium IAPEC, Johor Bahru, pp. 110-115, 2011.

[23] Carlos López-Franco, Jesús Hernández-Barragán, Alma Y. Alanis, Nancy Arana-Daniel, Michel López-Franco, "Inverse kinematics of mobile manipulators based on differential evolution," International Journal of Advanced Robotic Systems, vol. 15, no. 1, pp 1-22, 2018. 
[24] Antonio Benitez Ignacio Huitzil Azgad Casiano Jorge De La Calleja Medina M. A., "PUMA 560: Robot Prototype with Graphic Simulation Environment," Advances in Mechanical Engineering, vol. 2, no. 1, pp. 15-22, 2012.

[25] H. Benzater, S. Chouraqui, "PUMA 560 Trajectory Control Using NSGA-II Technique with Real Valued Operators," International Journal of Soft Computing, Mathematics and Control IJSCMC, vol. 3, no. 3, pp. 13-32, August 2014

[26] Y. I. Al-Mashhadany, “ANFIS-Inverse-Controlled PUMA 560 Workspace Robot with Spherical Wrist” Procedia Engineering Journal, vol. 41, pp. 700-709, 2012.

[27] Wahyu S. Pambudi et al, "Simulation design of trajectory planning robot manipulator," Bulletin of Electrical Engineering and Informatics, vol. 8, no. 1, pp. 196-205, March 2019.

\section{BIOGRAPHY OF AUTHOR}

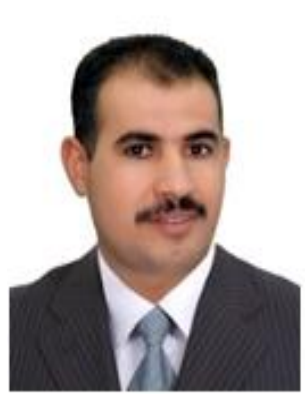

Assist. Prof. Dr. Yousif Ismail Mohammed Al-Mashhadany is a lecturer in Electrical Engineering Department-College of Engineering (Control Engineering). Senior member IEEE, He received the B.Sc. (1995), M.Sc. (1999), and Ph.D (2010) in Department of Electrical and Electronic Engineering from the Rashid School of Engineering and Science/University of Technology in Baghdad/Iraq. He completes postdoctoral fellow research in electrical engineering-control department at the University of Malaya in Malaysia (UMPEDAC) in 2012. He works since 2004, a lecturer in the Department of Electrical Engineering/Engineering College/University of Anbar. He has many publishing that included three books, two chapters, thirty seven Journals paper most of them (Clarivate, Scopus and international journal), and thirty two conferences paper. 